\title{
Resolution of left atrial appendage thrombus with apixaban
}

\author{
Tohru Kawakami*, Hiroko Kobayakawa, Hiroyoshi Ohno, Nobukiyo Tanaka and Hiroki Ishihara
}

\begin{abstract}
Left atrial appendage (LAA) thrombosis is an important cause of cardiogenic cerebral thromboembolism. Apixaban is a member of the class of novel oral anticoagulants (NOAC) and is superior to warfarin in preventing stroke or systemic embolism, causes less bleeding, and results in lower mortality in patients with atrial fibrillation. There are few reports of resolution of LAA thrombus with other NOAC. We present a 72-year-old male patient with persistent atrial fibrillation associated with left atrial thrombus. Sixteen days of apixaban treatment showed complete thrombus resolution. In this study, soluble fibrin and D-dimer levels decreased without prolongation of international normalized ratio (INR) and activated partial thromboplastin time (APTT).
\end{abstract}

Keywords: Atrial fibrillation, Left atrial appendage thrombus, Apixaban

\section{Background}

Left atrial appendage (LAA) thrombus is commonly associated with atrial fibrillation (AF) and causes thromboembolic complications. Warfarin is used for prevention of thromboembolic complications with AF patients and resolution of LAA thrombus [1]. Apixaban is a member of the class of novel oral anticoagulants (NOAC). It is superior to warfarin in preventing stroke or systemic embolism, and causes less bleeding [2]. Few reports exist detailing resolution of LAA thrombus with other novel oral anticoagulants (NOAC) $[3,4]$.

\section{Case presentation}

A 72-year-old male consulted our hospital due to dyspnea and palpitation, maintained for one week or more. On hospital admission the patient presented with functional NYHA class III; he had a clinical history of non-ischemic cardiomyopathy with severely impaired left ventricular function and a moderate AF-related thromboembolic risk with an actual $\mathrm{CHA}_{2} \mathrm{DS}_{2}$ VASc score of 3 , and had not been pretreated with anticoagulant. We determined that he required rapid anticoagulation to be delivered orally. We started oral anticoagulation (OAC) therapy with the direct factor Xa (FXa) inhibitor apixaban (5 mg twice daily). The patient had high levels of soluble fibrin (SF)

\footnotetext{
*Correspondence: tkawakami-ind@umin.ac.jp

From the Division of Cardiology, Ichinomiyanishi Hospital, 1 Kaimei-hira, Ichinomiya, Aichi, Japan
}

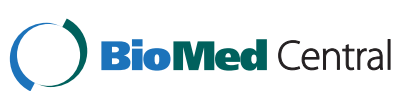

(c) 2013 Kawakami et al.; licensee BioMed Central Ltd. This is an Open Access article distributed under the terms of the Creative Commons Attribution License (http://creativecommons.org/licenses/by/2.0), which permits unrestricted use, distribution, and reproduction in any medium, provided the original work is properly cited. The Creative Commons Public Domain Dedication waiver (http://creativecommons.org/publicdomain/zero/1.0/) applies to the data made available in this article, unless otherwise stated. and D-dimer, normal levels of international normalized ratio (INR) and activated partial thromboplastin time (APTT) on hospitalization. We performed transesophageal echocardiography (TEE), which revealed formation of a small thrombus $(11 \times 10 \mathrm{~mm})$ in the left atrial appendage (LAA) (Figure 1A). After 16 days of apixaban treatment TEE showed complete thrombus resolution (Figure 1B). During apixaban treatment SF and D-dimer changed as the day passed; SF fell, while there was a rise and subsequent fall in D-dimer, without prolongation of INR or APTT (Figure 1C).

Finally, catheter ablation of persistent AF was performed successfully without clinical signs of cardiac embolism after 22 days of apixaban treatment and the patient was discharged in good medical condition under continued anticoagulant treatment with apixaban.

In this study we collected blood samples before breakfast. INR, PT, APTT, SF, and D-dimer were detectable in this trough period. All assays were performed in the laboratory of our institute. For quantitative determination of coagulation systems an automated coagulation analyzer was used (Coapresta 2000: Sekisui Medical Co., Ltd., Tokyo, Japan). PT was measured with Coagpia PT-N, whose international sensitivity index is almost equal to 1.0 (Sekisui Medical Co., Ltd.). APTT was measured with Coagpia APTT-N (Sekisui Medical Co., Ltd.). SF in sodium citrate plasma was measured with Nanopia SF (Sekisui Medical Co., Ltd.). D-dimer in sodium citrate 

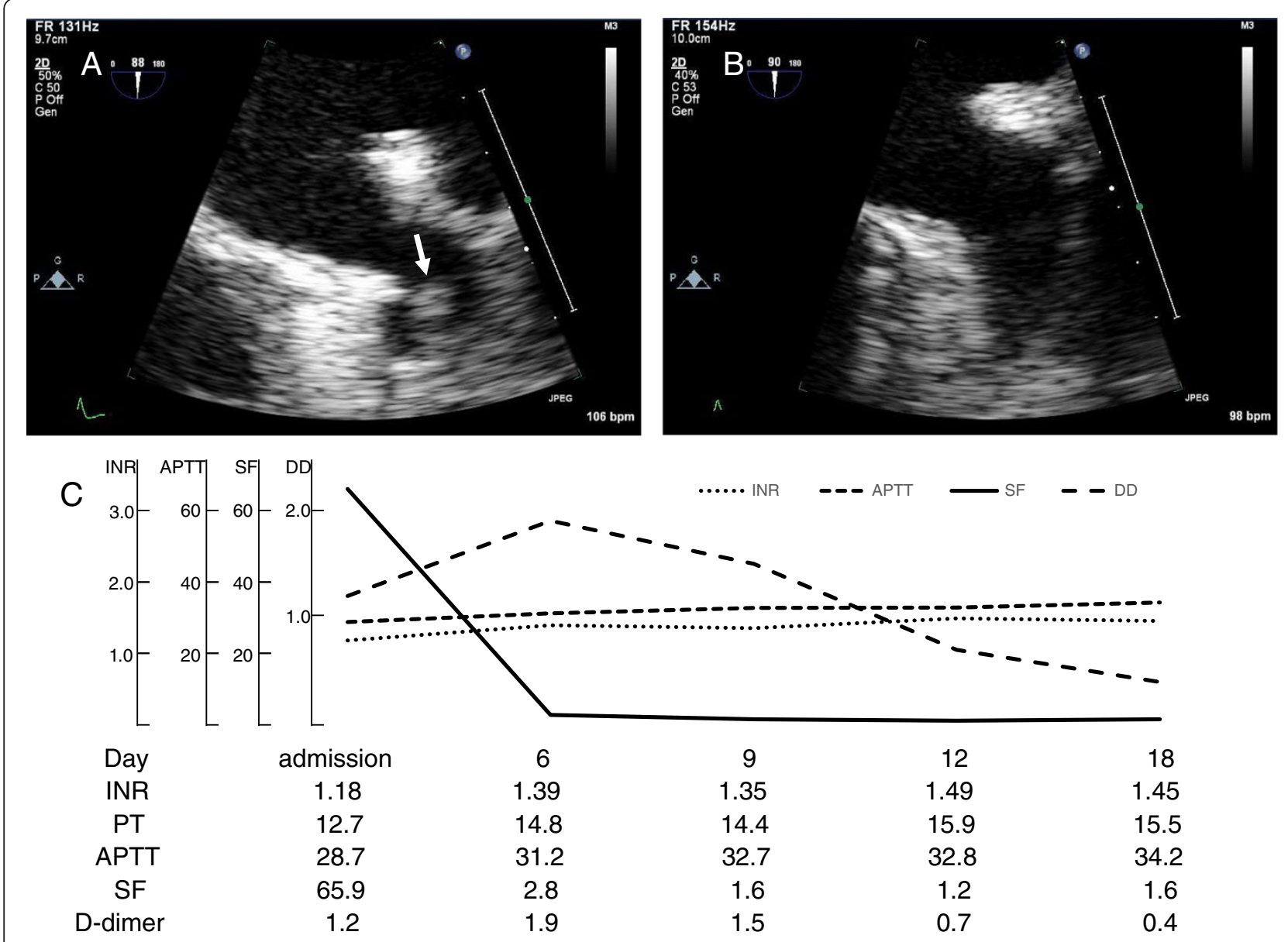

Figure 1 Transesophageal echocardiography and laboratory data for the coagulation system. A) Small thrombus formation (arrow) in the apex of the left atrial appendage (LAA) on day 4. B) Thrombus resolution after 16 days of anticoagulant therapy with apixaban. C) Plot of laboratory data for the coagulation system demonstrates a fall in SF, a rise and subsequent fall in D-dimer (DD), without prolongation of INR or APTT.

plasma was measured with Nanopia D-dimer (Sekisui Medical Co., Ltd.). Processing and analyses were performed within 90 minutes of sample collection.

\section{Discussion}

Apixaban is superior to warfarin in preventing stroke or systemic embolism, caused less bleeding, and resulted in lower mortality in patients with atrial fibrillation [2]. Resolution of LAA thrombus with warfarin has been previously reported [5]. There have been a few cases outlining resolution of LAA thrombus with other NOAC $[3,4]$.

To our knowledge this is the first documented case of LAA thrombus resolution under apixaban therapy and demonstrates the changes in laboratory data for the coagulation system. The optimal therapeutic range for anticoagulation with warfarin in the prevention of thromboembolic events with non-valvular AF patients extends over INR values of 2.0 to 3.0 [6,7]. It has been reported that major bleeding is observed only at INR values above 2.5 on anticoagulation with warfarin [1]. In this study, SF and D-dimer levels decreased without prolongation of INR and APTT.

Recently, SF and D-dimer levels have been considered useful for diagnosis of thrombosis [8-14]. The TEE-guided approach with short-term anticoagulation is considered to be as safe and clinically effective as the conventional approach, and is advocated in patients in whom earlier cardioversion would be clinically beneficial $[8,15,16]$. Addition of the TEE-guided approach to monitoring of fibrin-related markers such as SF and D-dimer may be safer than the simple TEE-guided approach for rhythm control strategy in AF patients.

Apixaban treatment enabled thrombus resolution within a manageable time period. Therefore, this NOAC could be considered to have an important role in rhythm control strategies in similar cases. It is of undoubted interest and requires further investigation in a larger population. 
In this case, we selected apixiaban. This was preferred to dabigatran treatment, which is associated with dyspepsia. Furthermore, rivaroxaban treatment was not powered for efficacy in the J-ROKET-AF study [17].

\section{Conclusions}

We report LAA thrombus resolution with apixaban. In this study, SF and D-dimer levels decreased along with LAA thrombus resolution without prolongation of INR and APTT.

\section{Consent}

Written informed consent was obtained from the patient for publication of this case report and any accompanying images. A copy of the written consent is available for review by the Editor-in-Chief of this journal.

\section{Abbreviations}

LAA: Left atrial appendage; NOAC: Novel oral anticoagulants; SF: Soluble fibrin; INR: International normalized ratio; APTT: Activated partial thromboplastin time; AF: Atrial fibrillation; OAC: Oral anticoagulation; FXa: Factor Xa; TEE: Transesophageal echocardiography.

\section{Competing interests}

Non-financial competing interests.

\section{Authors' contributions}

TK, MD, (Concept/design, Data analysis/interpretation). HK, MD, PhD, (Data collection). HO, MD, PhD, (Data collection). NT, MD, PhD, (Data collection). HI, MD, (Data collection). All authors read and approved the final manuscript.

Received: 5 September 2013 Accepted: 17 November 2013 Published: 20 December 2013

\section{References}

1. The European Atrial Fibrillation Trial Study Group: Optimal oral anticoagulant therapy in patients with nonrheumatic atrial fibrillation and recent cerebral ischemia. N Engl I Med 1995, 333:5-10.

2. Granger CB, Alexander JH, McMurray JJ, Lopes RD, Hylek EM, Hanna M, Al-Khalidi HR, Ansell J, Atar D, Avezum A, Bahit MC, Diaz R, Easton JD, Ezekowitz JA, Flaker G, Garcia D, Geraldes M, Gersh BJ, Golitsyn S, Goto S, Hermosillo AG, Hohnloser SH, Horowitz J, Mohan P, Jansky P, Lewis BS, Lopez-Sendon JL, Pais $P$, Parkhomenko A, Verheugt FW, et al: Apixaban versus warfarin in patients with atrial fibrillation. N Engl J Med 2011, 365:981-992.

3. Vidal A, Vanerio G: Dabigatran and left atrial appendage thrombus. J Thromb Thrombolysis 2012, 34:545-547.

4. Hammerstingl C, Potzsch B, Nickenig G: Resolution of giant left atrial appendage thrombus with rivaroxaban. Thromb Haemost 2013, 109:583-584.

5. Kimura M, Wasaki Y, Ogawa H, Nakatsuka M, Wakeyama T, Iwami T, Ono K, Nakao F, Matsuzaki M: Effect of low-intensity warfarin therapy on left atrial thrombus resolution in patients with nonvalvular atrial fibrillation: a transesophageal echocardiographic study. Jpn Circ J 2001, 65:271-274.

6. Anderson $\mathrm{J} L$, Halperin $\mathrm{JL}$, Albert NM, Bozkurt B, Brindis RG, Curtis LH, DeMets D, Guyton RA, Hochman IS, Kovacs RJ, Ohman EM, Pressler SJ, Sellke FW, Shen WK, Wann LS, Curtis AB, Ellenbogen KA, Estes NA 3rd, Ezekowitz MD, Jackman WM, January CT, Lowe JE, Page RL, Slotwiner DJ, Stevenson WG, Tracy CM, Fuster V, Ryden LE, Cannom DS, Crijns HJ, et al: Management of patients with atrial fibrillation (compilation of 2006 ACCF/AHA/ESC and 2011 ACCF/AHA/HRS recommendations): a report of the American college of cardiology/American heart association task force on practice guidelines. J Am Coll Cardiol 2006, 2013(61):1935-1944.

7. Nair CK, Holmberg MJ, Aronow WS, Shen X, Li H, Lakkireddy D: Thromboembolism in patients with atrial fibrillation with and without left atrial thrombus documented by transesophageal echocardiography. Am J Ther 2009, 16:385-392.
8. Habara S, Dote K, Kato M, Sasaki S, Goto K, Takemoto H, Hasegawa D, Matsuda O: Prediction of left atrial appendage thrombi in non-valvular atrial fibrillation. Eur Heart J 2007, 28:2217-2222.

9. Mitusch R, Siemens HJ, Garbe M, Wagner T, Sheikhzadeh A, Diederich KW: Detection of a hypercoagulable state in nonvalvular atrial fibrillation and the effect of anticoagulant therapy. Thromb Haemost 1996, 75:219-223.

10. Ota S, Wada H, Nobori T, Kobayashi T, Nishio M, Nishioka Y, Noda M, Sakaguchi A, Abe Y, Nishioka J, Ishikura K, Yamada N, Nakano T: Diagnosis of deep vein thrombosis by plasma-soluble fibrin or D-dimer. Am J Hematol 2005, 79:274-280.

11. Palareti G, Cosmi B, Legnani C, Tosetto A, Brusi C, lorio A, Pengo V, Ghirarduzzi A, Pattacini C, Testa S, Lensing AW, Tripodi A: D-dimer testing to determine the duration of anticoagulation therapy. N Engl J Med 2006, 355:1780-1789.

12. Ruiz-Gimenez N, Friera A, Artieda P, Caballero P, Sanchez Molini P, Morales M, Suarez C: Rapid D-dimer test combined a clinical model for deep vein thrombosis. Validation with ultrasonography and clinical follow-up in 383 patients. Thromb Haemost 2004, 91:1237-1246.

13. Wada H, Kobayashi T, Abe Y, Hatada T, Yamada N, Sudo A, Uchida A, Nobori T: Elevated levels of soluble fibrin or D-dimer indicate high risk of thrombosis. J Thromb Haemost 2006, 4:1253-1258.

14. Wells PS, Anderson DR, Rodger M, Forgie M, Kearon C, Dreyer J, Kovacs G, Mitchell M, Lewandowski B, Kovacs MJ: Evaluation of D-dimer in the diagnosis of suspected deep-vein thrombosis. N Engl J Med 2003, 349:1227-1235.

15. Klein AL, Grimm RA, Murray RD, Apperson-Hansen C, Asinger RW, Black IW, Davidoff R, Erbel R, Halperin JL, Orsinelli DA, Porter TR, Stoddard MF: Use of transesophageal echocardiography to guide cardioversion in patients with atrial fibrillation. N Engl J Med 2001, 344:1411-1420.

16. Klein AL, Murray RD, Grimm RA: Role of transesophageal echocardiography-guided cardioversion of patients with atrial fibrillation. J Am Coll Cardiol 2001, 37:691-704.

17. Hori M, Matsumoto M, Tanahashi N, Momomura S, Uchiyama S, Goto S, Izumi T, Koretsune Y, Kajikawa M, Kato M, Ueda H, Iwamoto K, Tajiri M: Rivaroxaban vs. warfarin in Japanese patients with atrial fibrillation - the J-ROCKET AF study. Circ J 2012, 76:2104-2111.

doi:10.1186/1477-9560-11-26

Cite this article as: Kawakami et al:: Resolution of left atrial appendage thrombus with apixaban. Thrombosis Journal 2013 11:26.

\section{Submit your next manuscript to BioMed Central and take full advantage of:}

- Convenient online submission

- Thorough peer review

- No space constraints or color figure charges

- Immediate publication on acceptance

- Inclusion in PubMed, CAS, Scopus and Google Scholar

- Research which is freely available for redistribution 